\title{
Temporal Dynamics of Phytophthora Blight on Bell Pepper in Relation to the Mechanisms of Dispersal of Primary Inoculum of Phytophthora capsici in Soil
}

\author{
L. S. Sujkowski, G. R. Parra, M. L. Gumpertz, and J. B. Ristaino
}

First author: Laboratory Corporation of America, Research Triangle Park, NC 27709; second and fourth authors: Department of Plant Pathology, North Carolina State University, Raleigh 27695; and third author: Department of Statistics, North Carolina State University, Raleigh 27695.

Accepted for publication 8 October 1999.

\begin{abstract}
Sujkowski, L. S., Parra, G. R., Gumpertz, M. L., and Ristaino, J. B. 2000. Temporal dynamics of Phytophthora blight on bell pepper in relation to the mechanisms of dispersal of primary inoculum of Phytophthora capsici in soil. Phytopathology 90:148-156.

The effect of components of primary inoculum dispersal in soil on the temporal dynamics of Phytophthora blight epidemics in bell pepper was evaluated in field and growth-chamber experiments. Phytophthora capsici may potentially be dispersed by one of several mechanisms in the soil, including inoculum movement to roots, root growth to inoculum, and root-to-root spread. Individual components of primary inoculum dispersal were manipulated in field plots by introducing (i) sporangia and mycelia directly in soil so that all three mechanisms of dispersal were possible, (ii) a plant with sporulating lesions on the soil surface in a plastic polyvinyl chloride (PVC) tube so inoculum movement to roots was possible, (iii) a wax-encased peat pot containing sporangia and mycelia in soil so root growth to inoculum was possible, (iv) a wax-encased peat

incidence of disease was highest in plots where sporangia and mycelia were buried directly in soil and all mechanisms of dispersal were operative (60 and 32\%) and where infected plants were placed in PVC tubes on the soil surface and inoculum movement to roots occurred with rainfall (89 and 23\%). Disease onset was delayed in 1995 and 1996, and final incidence was lower in plants in plots where wax-encased sporangia (6 and $22 \%)$ or wax-encased infected roots $(22 \%)$ were buried in soil and root growth to inoculum or root-to-root spread occurred. Incidence of root infections was higher over time in plots where inoculum moved to roots or all mechanisms of dispersal were possible. In growth-chamber studies, ultimately all plants became diseased regardless of the dispersal mechanism of primary inoculum, but disease onset was delayed when plant roots had to grow through a wax layer to inoculum or infected roots in tension funnels that contained small volumes of soil. Our data from both field and growth-chamber studies demonstrate that the mechanism of dispersal of the primary inoculum in soil can have large effects on the temporal dynamics of disease.
\end{abstract} pot containing infected roots in soil so root-to-root spread was possible, (v) noninfested V8 vermiculite media into soil directly as a control, or (vi) wax-encased noninfested soil as a control. In 1995 and 1996, final
Additional keywords: root disease, spatial dynamics.
Phytophthora blight, caused by the oomycete pathogen Phytophthora capsici Leonian, is a devastating disease on bell pepper and cucurbit crops in the United States and worldwide $(1,4,13,15$, 17,33). Management of the disease relies on integrated approaches, including alterations in cultural practices, host resistance, and use of fungicides (27). The disease has increased in severity in recent years and metalaxyl-resistant isolates have been found in the field $(1,20,21)$. Modifications of cultural and chemical management strategies can have large effects on specific spatial and temporal components of epidemic development of Phytophthora blight on bell peppers (29). Phytophthora blight was reduced most dramatically by a no-till cropping system in which pepper was planted into stubble from a fall-grown cover crop. The surface stubble probably suppressed splash dispersal of inoculum from soil to parts of plants above the ground.

$P$. capsici can infect virtually every part of the plant and the inoculum produced can contribute to subsequent spread in the field $(4,7,28)$. We are studying $P$. capsici on pepper as a model system to understand the modes of dispersal of inoculum in the field. We characterized changes in spatial and temporal patterns of disease symptoms including root, crown, and stem infections, caused by

Corresponding author: J. B. Ristaino; E-mail address: Jean_Ristaino@ncsu.edu

Publication no. P-1999-1129-03R

(C) 2000 The American Phytopathological Society naturally occurring inoculum of $P$. capsici in pepper fields over time $(16,28)$. Three primary mechanisms of dispersal of inoculum including inoculum movement from root-to-root in the soil (16), inoculum movement down rows with surface water or rainfall $(1,4,5)$, and splash dispersal from the soil to above-ground plant parts with rain or overhead irrigation water have been identified $(4,16,28)$.

Inoculum movement down rows with surface water is an important mechanism of dispersal for many polycyclic Phytophthora spp. $(8,19,25,31)$, and this was the predominant mechanism of dispersal of $P$. capsici in naturally infested fields in North Carolina and elsewhere $(4,6,16,27,28)$. Unidirectional spread of the pathogen along the rows over long distances has been observed repeatedly in bell-pepper fields due to rainfall or irrigation events $(5,6,24,27,28)$. High rates of disease increase will occur when splash dispersal of inoculum from soil to aerial parts of plants occurs with rainfall or overhead irrigation events. There may be two-dimensional expansion of disease foci and new foci will generally occur close to existing foci, as has been demonstrated in the $P$. cactorum leather-rot system on strawberry (23). If the primary mechanism of spread is over longer distances by aerial dispersal of inoculum, as in the $P$. infestans pathosystem on potato, the rate of disease increase will be high and the degree of aggregation of disease will decrease rapidly as focal expansion occurs (34). Aerial dispersal has not been described in Phytophthora blight epidemics on bell pepper, but local splash dispersal is common $(16,28)$. 
In our previous work on the analysis of the spatial dynamics of disease symptom expression, primary inoculum of $P$. capsici in the soil caused initial root infections that progressed to crown infection (28). Wilting almost always preceded crown lesion development, suggesting that root infections also are important for subsequent disease development. If inoculum spread involves movement in soil, either via root growth to inoculum, inoculum movement to roots, or root-to-root spread of the pathogen, the change in spatial pattern of disease should occur slowly $(28,30)$. The primary change in disease pattern will occur within rows, the occurrence of new foci may be rare, and the degree of aggregation of disease will change little with time.

Little is known about the primary mechanisms of dispersal of $P$. capsici within the soil. Most studies have focused on the effect of soil physical factors, particularly the matric component of soil water potential, on disease $(2,3,11,26)$. In the research presented here, we extend our studies of $P$. capsici on pepper to develop a more complete understanding of the modes of primary inoculum dispersal of $P$. capsici in soil. The objective of this study was to determine which component or components of primary inoculum dispersal in soil had the greatest impact on the temporal dynamics of the disease on roots and aboveground portions of plants in the field. In addition, growth-chamber studies were conducted under controlled soil moisture conditions to evaluate the components of primary inoculum dispersal in soil. A preliminary report of a portion of this research has been presented (32).

\section{MATERIALS AND METHODS}

Inoculum production for field experiments. Cultures of $P$. capsici were maintained on cornmeal agar slants at $25^{\circ} \mathrm{C}$. Cultures of P. capsici of either isolate B1HB14 (A1 mating type) or B2HH4 (A2 mating type) were grown for 2 weeks on V8 juice agar at $25^{\circ} \mathrm{C}$. Cultures were flooded with sterile distilled water for 3 to 5 days at $25^{\circ} \mathrm{C}$ and placed at $4^{\circ} \mathrm{C}$ for $2 \mathrm{~h}$ to stimulate zoospore release. Zoospores were harvested from each isolate separately, counted using a hemacytometer, and concentrations were adjusted to $5.0 \times 10^{4} / \mathrm{ml}$. Zoospore suspensions of each isolate were mixed $1: 1$ ( vol/vol) prior to inoculation. Pepper plants (4 weeks old) were transplanted to plastic pots $(15 \mathrm{~cm}$ diameter $)$ in the greenhouse and inoculated 2 weeks later by pipetting $10 \mathrm{ml}$ of a $5.0 \times$ $10^{4}$ zoospore suspension into four holes $(1 \mathrm{~cm}$ diameter) spaced evenly around the root zone of each plant. Initial inoculum densities in soil were $1.0 \times 10^{4} \mathrm{CFU} / \mathrm{g}$ of soil. Plants were incubated for 1 week under greenhouse conditions $\left(25\right.$ to $\left.28^{\circ} \mathrm{C}\right)$ until sporulating lesions were visible and then used as a point source for inoculum movement to roots in the field.

Inoculum of $P$. capsici, consisting of sporangia and mycelia, was prepared for soil infestation by culturing the fungus at $25^{\circ} \mathrm{C}$ for 3 to 4 weeks in 1-liter jars containing $500 \mathrm{~cm}^{3}$ of vermiculite amended with $250 \mathrm{ml}$ of V8 broth $(200 \mathrm{ml}$ of V8, $800 \mathrm{ml}$ of distilled water, $2 \mathrm{~g}$ of $\mathrm{CaCO}_{3}$ per liter). Jars containing the V8 vermiculite medium were autoclaved for $1 \mathrm{~h}$ at $121^{\circ} \mathrm{C}$ on two consecutive days. The V8 vermiculite medium was inoculated with 10 agar plugs $(\approx 5 \mathrm{~mm}$ in diameter) removed from 10 - to 14-dayold cultures of either P. capsici isolate B1HB14 or B2HH4. Equal proportions $\left(500 \mathrm{~cm}^{3}\right)$ of inoculum of each isolate were added to fumigated field soil at a rate of 1:1, soil/inoculum ( $\mathrm{vol} / \mathrm{vol}$; $500 \mathrm{~cm}^{3}$ V8 vermiculite medium $=445 \mathrm{~g}$ ). Initial inoculum densities were $7.0 \times 10^{3} \mathrm{CFU} / \mathrm{g}$ of soil.

Pepper plants were inoculated with a $1: 1(\mathrm{vol} / \mathrm{vol})$ mixture of zoospores from isolates B1HB14 and B2HH4 as described above to produce infected roots for subsequent use. Roots showing severe symptoms of root rot were removed from the pots after 2 weeks, rinsed with sterile distilled water, blotted dry, and weighed. Approximately $750 \mathrm{~g}$ of roots was shredded and mixed into 10 liters of fumigated field soil. Initial inoculum densities in soil were $8.4 \times$ $10^{3} \mathrm{CFU} / \mathrm{g}$ of soil.
Commercial peat pots $\left(250 \mathrm{~cm}^{3}\right.$ volume $)$ were dipped in a 1:5 (vol/vol) mixture of beeswax (Cheatham Chemical Co., Stone Mountain, GA) and petroleum jelly. Soil $\left(250 \mathrm{~cm}^{3}\right)$ infested with sporangia and mycelia as described above was placed in wax-encased peat pots to provide a source of inoculum for root growth to inoculum. A top was made from extra peat pots to cover the infested soil in the pots, and the peat pots were sealed with the waxpetroleum jelly mixture to prevent inoculum movement from the pots. Soil $\left(250 \mathrm{~cm}^{3}\right)$ containing infested roots as described above was placed in wax-encased peat pots to provide a source of inoculum for root-to-root spread of inoculum. The wax-encased peat pots allowed roots from nearby pepper plants to grow into the inoculum source (sporangia and mycelia or infected roots) but provided a barrier for inoculum movement out of the peat pots.

Field plots. Field experiments were conducted in 1995 and 1996 at Central Crops Research Station in Clayton, NC, in two locations on loamy sand soil. The soil in the 1995 field site contained $84.1 \%$ sand, $5 \%$ clay, and $10.9 \%$ silt, and the soil at the 1996 site contained $84.7 \%$ sand, $3.6 \%$ clay, and $11.4 \%$ silt. All plots were broadcast fumigated with methyl bromide-chloropicrin (98-2; $392 \mathrm{~kg} / \mathrm{ha}$ ) under clear plastic to eliminate residual inoculum of $P$. capsici in the field. Plastic was removed after fumigation and beds were shaped. Beds were $\approx 90 \mathrm{~cm}$ wide and $21 \mathrm{~m}$ long. Each experimental unit (the unit to which treatments were applied) consisted of two double-row beds (A and B) that were $152 \mathrm{~cm}$ wide (Fig. 1). Each bed was divided into five quadrats that were $3 \mathrm{~m}$ long. Each quadrat was planted with 20 plants and treated identically within the double-row beds (Fig. 1). Disease was rated in both plots A and $\mathrm{B}$, but only the B plots were destructively sampled during the season. Pepper seedlings of cv. Keystone Resistant Giant (6 weeks old) were transplanted in early June and plant spacing was $30 \mathrm{~cm}$. Plots were infested $\approx 1$ week after transplanting in each year. Noninfested borders that were $1 \mathrm{~m}$ long separated quadrats within a bed and were also planted with pepper.

Six treatments were imposed in the field that specifically favored different mechanisms of pathogen dispersal in soil. In each treatment, a point source of inoculum was placed in the center of each quadrat within the double-row beds (Fig. 1). There were 10 point sources of inoculum (five quadrats per bed) in each experimental unit. In treatment one, sporangia and mycelia in V8 vericulite were placed directly in soil $\approx 20 \mathrm{~cm}$ deep in the center of

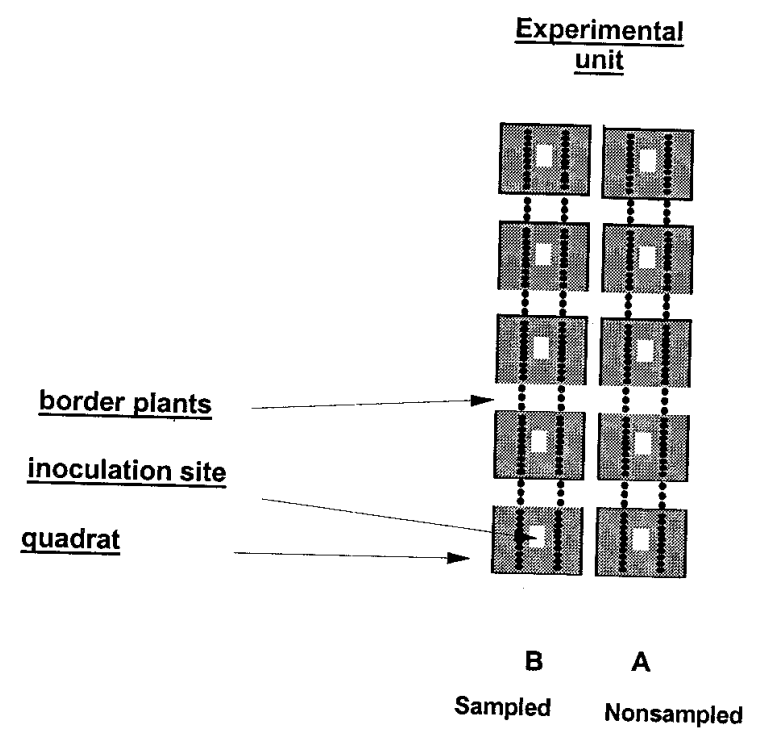

Fig. 1. Diagram of the design of each experimental unit in the field. Two double-row plots labeled A and B were divided into five quadrats, each containing 20 plants. Three border plants were planted between each quadrat and at the ends of rows. Plots had a point source of inoculum in the center of each of the five quadrats. Plots were replicated four times in the field; there were six treatments. 
each quadrat at a rate of $500 \mathrm{~cm}^{3}$ per inoculation site. Inoculum was freely placed in soil; therefore, all three mechanisms of dispersal including, inoculum movement to roots, root growth to inoculum, and root-to-root contact, were possible in this treatment. In treatment two, inoculum movement to roots was encouraged by placing a pepper plant with sporulating lesions in a PVC tube, $\approx 60 \mathrm{~cm}$
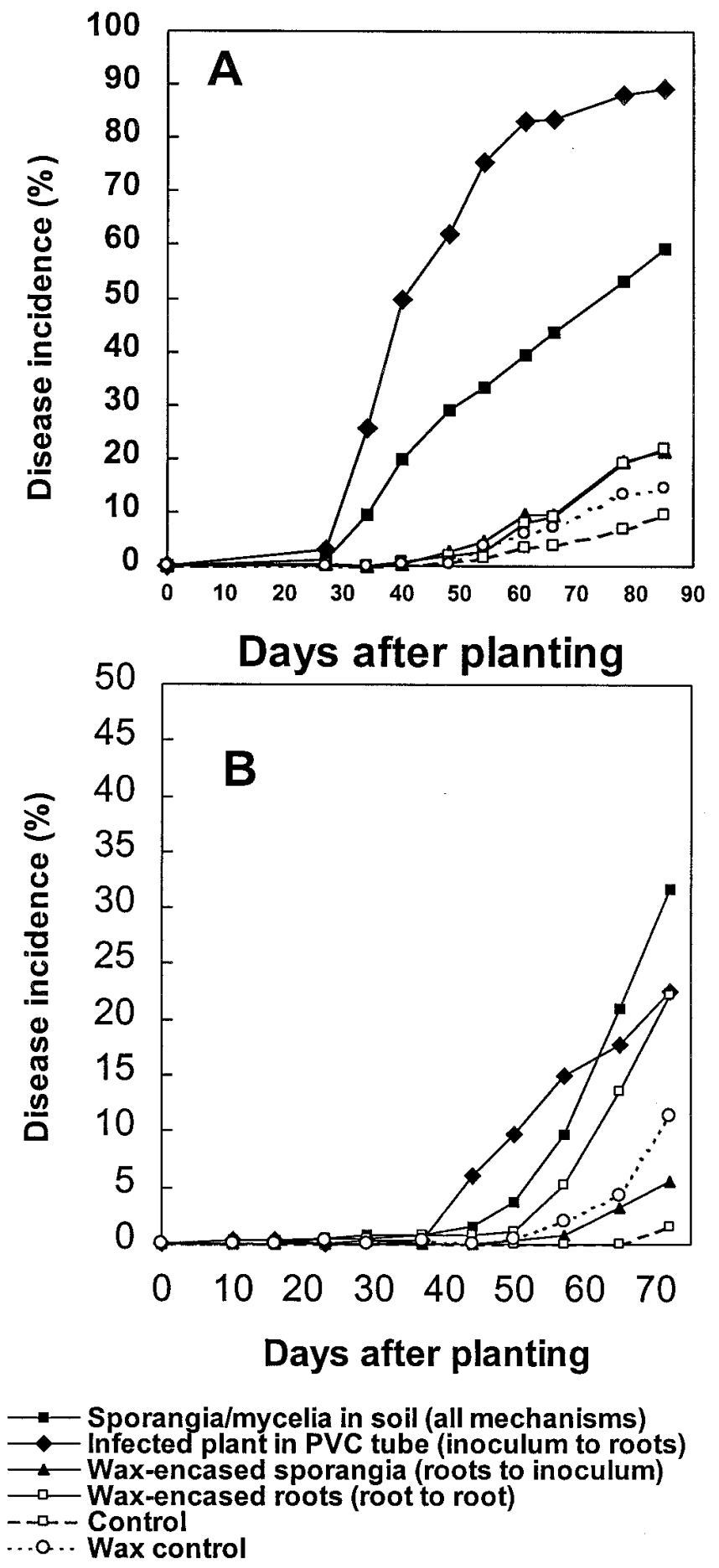

Fig. 2. Effect of components of primary inoculum dispersal in soil on temporal dynamics of Phytophthora blight, caused by Phytophthora capsici, on bell pepper in A, 1995 and B, 1996. Inoculum sources included: sporangia and mycelia buried directly in soil (all mechanisms of dispersal), infected plant in PVC tube on soil surface (inoculum movement to roots), wax-encased sporangia and mycelia buried in soil (root growth to inoculum), and wax-encased infected roots buried in soil (root-to-root spread). Controls included noninfested and wax-encased noninfested soil. Each point on the graph represents the mean disease incidence over five quadrats in the A plots and four replicated plots. high and $10 \mathrm{~cm}$ diameter, on the soil surface in the center of each quadrat. PVC tubes were pushed firmly into soil to stabilized them. Sporangia washed from plants to soil with rainfall and moved to roots to foster inoculum movement to roots. In treatment three, sporangia and mycelia in wax-encased peat pots were placed in soil $\approx 20 \mathrm{~cm}$ deep in the center of each quadrat, so roots had to grow to inoculum. In treatment four, infected roots in wax-encased peat pots were placed in soil $\approx 20 \mathrm{~cm}$ deep in the center of each quadrat so root-to-root spread could occur. In treatment five, noninfested V8 vermiculite media $\left(500 \mathrm{~cm}^{3}\right)$ was placed directly in soil as a control. In treatment six, wax-encased peat pots containing noninfested V8 vermiculite media were placed in soil as a control. Each of the six treatments was replicated four times in a randomized complete block design, and the experiment was conducted during two successive years. Plots were irrigated twice weekly during the growing season by subsurface drip-irrigation. The irrigation line was in the center of the beds $\approx 10 \mathrm{~cm}$ below the soil surface.

Disease rating and sampling. All plants in both plots A and B were rated weekly for incidence of wilted plants, plants with crown lesions, stem lesions, leaf lesions, fruit lesions, or dead plants. Early in epidemic development, most plants exhibited symptoms of either wilting or crown lesions. Fruit and leaf lesions were not common. A plant was considered diseased if it exhibited symptoms in any class, and the mean total incidence of disease within each quadrat was calculated in plot A for each treatment-replicate combination over time.

In addition, in the B plots, all 20 plants from one quadrat of each treatment-replicate combination were removed, and root disease severity was assessed four times during the season. Quadrats chosen for destructive sampling in the B plots were randomized. Roots were rated for disease severity on a scale of 0 to 4 , where $0=$ no disease; and $1 \geq 0$ to $25 \%, 2 \geq 25$ to $50 \%, 3 \geq 50$ to $75 \%$, and $4 \geq$ 75 to $100 \%$ root rot. The incidence of root disease within each quadrat at a given sampling time was calculated. The population density of the fungus in roots was determined. Representative root samples were disinfested in $0.05 \%$ sodium hypochlorite, rinsed in distilled water, and plated on a selective medium used for root isolations (14). Colonies of P. capsici were counted 40 to $72 \mathrm{~h}$ after incubation in the dark at $25^{\circ} \mathrm{C}$, and the number of colony forming units per gram of fresh root weight was calculated.

Levels of inoculum of $P$. capsici in soil were assayed immediately after placement in soil and at four times during the season at the same time that root disease severity was evaluated in the B plots. Inoculum sources from the point source and soil cores were removed at each sampling time from the B plots to measure population densities of the pathogen in soil. Soil cores were removed from around the four central plants near the point source of inoculum at the first and the second sampling time and from around eight central plants near the point source of inoculum at the third sampling time. Soil cores adjacent to all 20 plants in the quadrat were sampled at the last sampling time. Two cores $(\approx 1.97 \times 20 \mathrm{~cm})$ were removed at a distance of $5 \mathrm{~cm}$ on each side of the plant and placed in plastic bags. Soil was held at room temperature and assayed within 2 days after sampling. Soil was diluted in $0.25 \%$ water agar at a rate of $2 \mathrm{~g} / 98 \mathrm{ml}$ of water agar (1:50, wt/vol) from initially infested sites or at a rate of $20 \mathrm{~g} / 80 \mathrm{ml}$ of water agar (1:5, wt/vol) from all other sampling sites. One subsample of soil was used for each soil dilution. A 1-ml sample from each dilution was spread onto each of five replicate plates of Masago medium (18) amended with hymexazol at $20 \mathrm{~g} / \mathrm{ml}(99.5 \%$ a.i.). Petri dishes were incubated at $25^{\circ} \mathrm{C}$ in the dark for 48 to $72 \mathrm{~h}$ and rinsed with water, and colonies of $P$. capsici were counted. Gravimetric water content of soil samples at each location was calculated. Inoculum density was defined as the number of colony forming units per gram of dry soil.

Marketable yield was measured at harvest on pepper fruits from the A plots. Pepper fruits larger than $5 \mathrm{~cm}$ in diameter were collected from each of the five quadrats and weighed, and average yield was calculated per plot. 
Growth-chamber experiments. Experiments were conducted in the growth chamber under controlled soil moisture conditions to determine the relative importance of infection via root growth to inoculum, inoculum movement to roots, or root-to-root spread on the temporal dynamics of disease. Six treatments similar to those imposed in the field were used to separate distinct mechanisms of inoculum dispersal in soil. Inoculum was prepared in the same way as described for the field experiments. Experiments were conducted in PVC tubes $(7.5 \mathrm{~cm}$ diameter $\times 6.0 \mathrm{~cm}$ high) placed in 350-ml Buchner tension funnels (10). Treatment one consisted of soil infested with V8 vermiculite containing sporangia and mycelium at rates similar to those described for the field experiment. Treatment one was imposed to allow all mechanisms of dispersal, including root growth to inoculum, inoculum movement to roots, and root-to-root contact, to occur. The inoculum-soil mixture was placed in the bottom half of the plastic cylinder that was placed in the tension funnel. Noninfested soil was placed in the top half of the plastic cylinder. In treatment two, $5 \mathrm{ml}$ of a zoospore suspension $\left(2.5 \times 10^{4}\right.$ zoospores per $\left.\mathrm{ml}\right)$ was pipetted into noninfested soil in the plastic cylinders and funnel heights were adjusted to allow inoculum movement to roots. In treatment three, soil infested 1:1 ( $\mathrm{vol} / \mathrm{vol})$ with V8 vermiculite media containing sporangia and mycelia was placed in the bottom half of the plastic cylinder in the tension funnel. A 3- to 4-mm layer of beeswax-petroleum jelly $(1: 5, \mathrm{vol} / \mathrm{vol})$ was poured directly on the soil surface and around the interior edge of the plastic cylinder to separate infested soil from noninfested soil. Noninfested soil was placed in the top half of the cylinder. Root growth to inoculum was promoted because seedling roots had to penetrate the wax layer to contact inoculum. In treatment four, soil containing infected roots (as described for the field experiments) was placed in the bottom half of the plastic cylinder in the tension funnel, and the wax layer was applied as in treatment three. Noninfested soil was placed in the top half of the cylinder. Root-to-root spread of disease was promoted because seedling roots had to penetrate the wax layer to contact infected roots. Control treatments consisted of soil mixed 1:1 (vol/vol) with noninfested V8 vermiculite media or noninfested soil in treatments five and six, respectively. In treatment six, soil in the bottom half of the cylinder was separated from soil in the top half of the cylinder with a wax layer. There was no wax layer in treatment five. Five pepper seedlings of cv. Keystone Resistant Giant (4 weeks old) were transplanted into each plastic cylinder, and roots were covered with $150 \mathrm{~cm}^{3}$ of noninfested field soil. Initially, soil in all funnels was brought to saturation, then drained to a constant soil water matric potential of $10 \mathrm{~J} / \mathrm{kg}^{-1}$ through the duration of the experiment, which was conducted for 3 weeks. Soil in funnels above the wax layers was watered daily by pipetting $5 \mathrm{ml}$ of deionized water on the soil surface. Individual PVC tubes in the funnels were covered with plastic bags to prevent desiccation. The experiment was set up in a randomized complete block design, and there were three replicates. Each experimental unit was composed of three funnels with PVC tubes. The experiments were repeated three times.

Plants were rated daily for incidence of disease. Plants from one funnel from each treatment and replication were destructively sampled each week to evaluate root-disease incidence and severity and to measure the density of inoculum in soil and in roots. Roots were removed from soil, surface-sterilized for $45 \mathrm{~s}$ in $0.05 \%$ sodium hypochlorite, rinsed with distilled water, and plated on KannwischerMitchell (KM) medium (14). Petri dishes were incubated for 48 to $72 \mathrm{~h}$ in the dark at $25^{\circ} \mathrm{C}$. Colonies were counted and the number of colony forming units per gram of root fresh weight was determined. Soil was removed from the top half of the cylinder and diluted 1:5 $(10 \mathrm{~g} / 40 \mathrm{ml})$ or 1:50 $(2 \mathrm{~g} / 98 \mathrm{ml})$ in $0.25 \%$ water agar, and $1 \mathrm{ml}$ of each sample was spread on each of five plates of Masago medium amended with hymexazol (18). Plates were incubated at $25^{\circ} \mathrm{C}$ in the dark for 48 to $72 \mathrm{~h}$, rinsed with water, and colonies were counted. The number of colony forming units per gram of dry soil was calculated. Masago's medium is routinely used for isolation of $P$. capsici from soil dilutions, because it contains more antibiotics than KM medium, which is used for root isolations $(14,18)$.

Statistical analyses. Percent data were subjected to an angular transformation (arcsine square root) to normalize the variance prior to analysis. Mean disease incidence over time, as well as inoculum densities of $P$. capsici in roots and soil, were calculated for each treatment-replicate combination. Field data were analyzed with multivariate repeated measures analysis of variance with Wilk's lambda statistics, using the polynomial option to separate the effects of time, block, and treatment. Final disease incidence and marketable yield at harvest were analyzed with analysis of variance. All data were analyzed with the Statistical Analysis System for PC's (SAS Institute, Cary, NC). Data from only one experiment are presented for growth-chamber experiments, because repeated experiments gave similar results.

\section{RESULTS}

Field experiments. Final disease incidence in 1995 was greatest and progressed fastest in plots where infected plants were placed in PVC tubes on the soil surface and inoculum movement to roots with rainfall events was possible (Fig. 2A). The timetreatment interaction was significant $(P>0.0001)$. Final disease incidence was $89 \%$ in these plants and increased to a greater extent over time than in plants in all the other treatments (Fig. 2A, Table 1). Disease also progressed rapidly in plots where sporangia and mycelia were buried directly in soil and all mechanisms of dispersal were possible. Final disease incidence was $60 \%$ in plants in these plots and was significantly higher than in plots where waxencased sporangia and mycelia or wax-encased roots were buried in soil (Fig. 2A, Table 1). In 1996, the time-treatment interaction was not significant and overall levels of disease were lower than in 1995. Disease onset occurred first in plots where infected plants were placed in PVC tubes on the soil surface and inoculum movement to roots occurred, as in 1995. However, final disease incidence was highest in plants in plots where sporangia and mycelia inoculum were buried directly in soil and all mechanisms of dispersal were possible (Fig. 2B, Table 1).

Disease onset was delayed until 48 and 65 days after planting, and final disease incidence was 22 and $6 \%$ in 1995 and 1996, respectively, when wax-encased sporangia and mycelia were buried

TABLE 1. Effect of mechanisms of primary inoculum dispersal of Phytophthora capsici in soil on final incidence of disease and marketable yield of bell pepper

\begin{tabular}{|c|c|c|c|c|}
\hline \multirow[b]{2}{*}{ Treatment (mechanism of dispersal) } & \multicolumn{2}{|c|}{ Final disease incidence $(\%)$} & \multicolumn{2}{|c|}{ Fruit yield (kg/plot) } \\
\hline & 1995 & 1996 & 1995 & 1996 \\
\hline Sporangia and mycelia in soil (all mechanisms) & 60.0 & 32.0 & 11.6 & 11.9 \\
\hline Infected plant in PVC tube (inoculum to roots) & 89.0 & 23.0 & 4.4 & 14.4 \\
\hline Wax-encased infected roots (root-to-root spread) & 22.0 & 22.0 & 25.3 & 15.2 \\
\hline Noninfested control & 9.5 & 1.5 & 22.9 & 11.6 \\
\hline Wax-encased control & 14.5 & 11.5 & 20.5 & 9.9 \\
\hline
\end{tabular}

${ }^{\mathrm{a}}$ Least significant difference for comparison of final disease incidence and fruit yield in 1995 and 1996. 
in soil and root growth to inoculum was the presumptive mechanism of dispersal (Fig. 2, Table 1). Disease onset also was delayed until 54 and 57 days after planting in 1995 and 1996, respectively, when wax-encased roots were buried in soil and root-to-root spread of inoculum was the presumptive mechanism of dispersal. In 1995 and 1996, final disease incidence was $22 \%$ in plants in plots where wax-encased roots or wax-encased sporangia and mycelia were buried in soil (Table 1). In 1996, final disease incidence was significantly higher in plants in plots where wax-encased roots were buried in soil than for wax-encased sporangia and mycelia (Table 1).
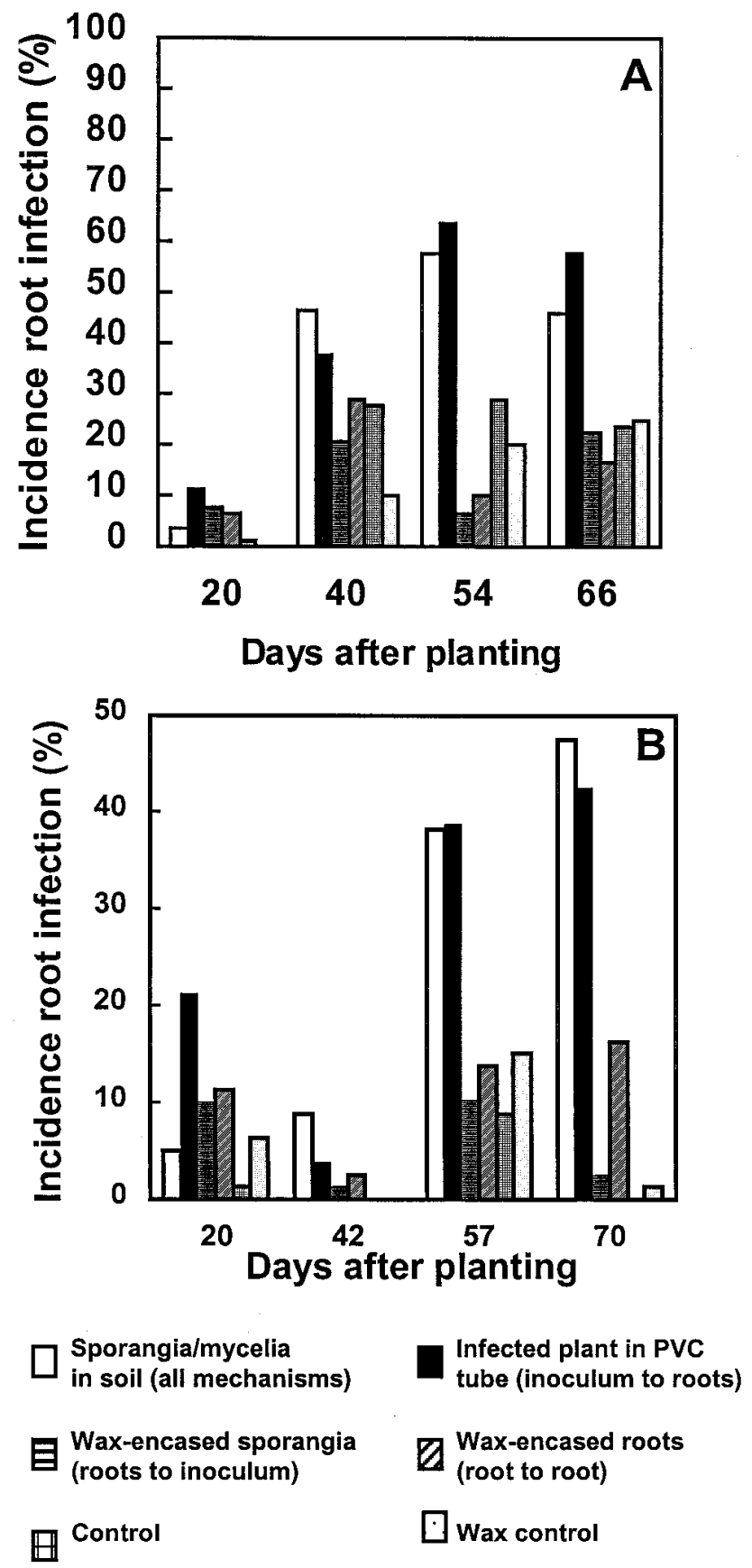

Fig. 3. Incidence of root infection caused by Phytophthora capsici in bell pepper in the field over time, as affected by components of primary inoculum dispersal in soil in A, 1995 and B, 1996. Inoculum sources included: sporangia and mycelia buried directly in soil (all mechanisms of dispersal), infected plant in PVC tube on soil surface (inoculum movement to roots), waxencased sporangia and mycelia buried in soil (root growth to inoculum), and wax-encased infected roots buried in soil (root-to-root spread). Controls included noninfested and wax-encased noninfested soil. $\mathrm{LSD}_{0.05}=13.86$ in 1995 and 9.96 in 1996 for the final sampling time.
Disease occurred in the control plots that were noninfested and the wax control plots at the end of the season in both years (Fig. $2 \mathrm{~A}$ and $\mathrm{B})$. There was significantly less disease in the control plots than other plots at the end of the season in 1995, and the treatment-time effect was significant (Fig. 2A, Table 1). The pathogen spread into the wax control plots by 70 days after planting in 1996, and final disease incidence was higher than in plots where wax-encased sporangia and mycelium were buried in soil. Overall levels of disease were lower in 1996 (Fig. 2B) than 1995 (Fig. 2A). The amount and timing of rainfall events differed between years. In 1995, $32.8 \mathrm{~cm}$ of rainfall occurred during early June,
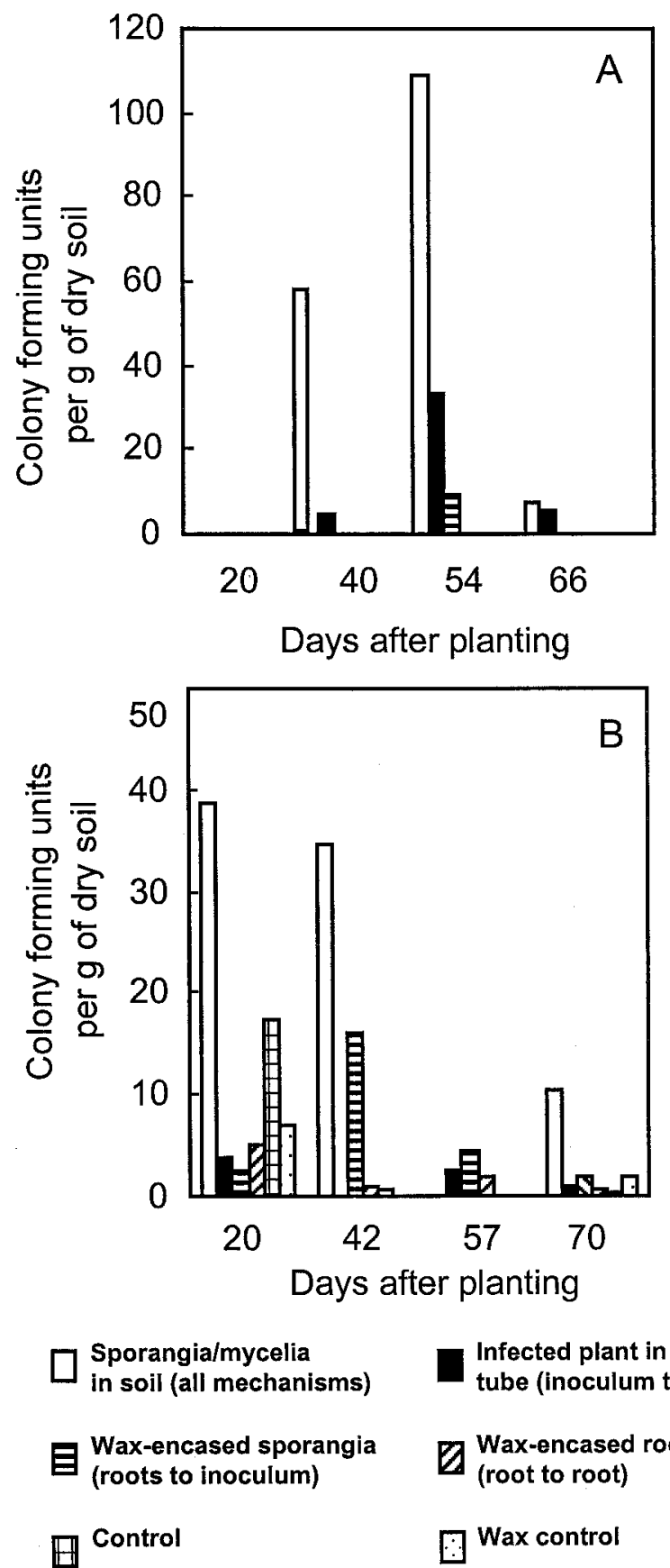

Infected plant in PVC tube (inoculum to roots)

$\square$ Wax-encased roots (root to root)

Wax control

Fig. 4. Propagule densities of Phytophthora capsici in soil, as affected by components of primary inoculum dispersal in A, 1995 and B, 1996. Inoculum sources included: sporangia and mycelia buried directly in soil (all mechanism of dispersal), infected plant in PVC tube on soil surface (inoculum movement to roots), wax-encased sporangia and mycelia buried in soil (root growth to inoculum), and wax-encased infected roots buried in soil (root-to-root spread). Controls included noninfested and wax-encased noninfested soil. 
after inoculation, whereas in 1996, only $5.8 \mathrm{~cm}$ of rainfall occurred during the same time period.

Incidence of root infection in 1995 increased significantly over time in all treatments $(P=0.0006)$, but the time-treatment interaction was not significant. The final incidence of root disease was higher $(P<0.0001)$ in plants in plots where sporangia and mycelia were buried directly in soil and all mechanisms of dispersal were possible and where infected plants were placed in PVC tubes and inoculum movement to roots was possible than in other treatments in both years (Fig. 3A and B). The time-treatment interaction was significant in $1996(P=0.0036)$ and disease increased to a greater extent over time in plants in these plots than in plants in the plots with wax-encased inoculum or control plots. Overall levels of root infection were lower in 1996 (Fig. 3B) than 1995 (Fig. 3A).

The highest level of inoculum recovered from roots coincided with the period of rapid increase in the development of epidemics on aboveground portions of plants in both years (Fig. 2). In 1995, the highest number of colony forming units of $P$. capsici per gram of roots occurred 40 days after planting in plants in plots where infected plants were placed in PVC tubes $(0.75 \mathrm{CFU} / \mathrm{g}$ of root) and in plants in plots where sporangia and mycelia were buried directly in soil (1.5 CFU/g of root). Low levels of inoculum were recovered from roots in these same plots 54 days after planting, and little inoculum was recovered from roots in plots in other treatments. No significant time-treatment interaction was found in $1995(P=0.3402)$. In 1996 , the highest number of colony forming units of $P$. capsici per gram of root occurred in plots where sporangia and mycelia were buried directly in soil (6.5 and 10.0 CFU/g of root) at 42 and 57 days after planting. This also coincided with the period of disease increase at 42 and 57 days after planting on aboveground portions of plants in these treatments (Fig. 2B). The time effect on root colonization was significant in $1996(P=0.0144)$; however, time-treatment interactions were not significant. Low levels of inoculum were recovered in roots from other treatments.

The highest propagule densities of P. capsici in soil (57 and 109 $\mathrm{CFU} / \mathrm{g}$ ) occurred at 40 and 54 days after planting where sporangia and mycelia were buried directly in soil and all mechanisms of dispersal were possible (Fig. 4A). Propagule densities of $P$. capsici in soil increased over time up to 54 days after planting in these plots but changed little in other plots, and the time-treatment interaction was significant in $1995(P=0.0008)$. Propagule densities of $33 \mathrm{CFU} / \mathrm{g}$ of soil occurred at 54 days after planting where infected plants were placed in PVC tubes and inoculum movement to roots was possible (Fig. 4A). Low levels of inoculum were detected in soil in plots where wax-encased sporangia and mycelia or wax-encased infected roots were buried in soil. In 1996, the highest propagule densities in soil (39 and $35 \mathrm{CFU} / \mathrm{g}$ ) occurred at 20 and 42 days, respectively, after planting in plots where sporangia and mycelia were buried directly in soil and all mechanisms of dispersal were possible (Fig. 4B). Lower levels of inoculum were detected in soil in plots from other treatments, as was demonstrated in 1995.

Marketable yield of pepper fruit at harvest in 1995 was reduced by $80 \%(P<0.01)$ compared with noninfested controls in plots where infected plants were placed in PVC tubes and inoculum movement to roots was possible (Table 1). Marketable yield of pepper fruit was reduced by $50 \%$ compared with noninfested controls in plots where sporangia and mycelia were buried directly in soil and all mechanisms of dispersal were possible (Table 1). In plots where wax-encased sporangia and mycelia or roots were buried in soil, yields were not significantly different from the noninfested control plots in 1995 (Table 1). In 1996, overall yields were lower in all treatments than in 1995, and yields did not differ significantly between treatments.

Growth-chamber experiments. Disease increased with time $(P<$ $0.01)$ and progressed significantly faster in plants where zoospore inoculum moved to roots and where sporangia and mycelia were buried directly in soil than in other treatments in the growth-chamber tests (Fig. 5A). When sporangia and mycelia or infected roots were separated from growing roots by a wax layer, disease onset was delayed by 7 and 5 days, respectively (Fig. 5A). Final disease incidence was ultimately high in plants in all treatments (Fig. 5A) and was $100 \%$ in most treatments and $87 \%$ in plants where infection occurred via infected roots through the wax layer.

Population densities of $P$. capsici in soil decreased slightly over time from $1.87 \times 10^{3} \mathrm{CFU} / \mathrm{g}$ at 11 days after planting to $1.05 \times$ $10^{3} \mathrm{CFU} / \mathrm{g}$ at 24 days after planting in soil from plants where sporangia and mycelia were buried directly in soil. Population densities of $P$. capsici in soil increased over time and highest values of $7 \times 10^{2}, 2.3 \times 10^{3}$, and $1.56 \times 10^{3} \mathrm{CFU} / \mathrm{g}$ of soil occurred 24 days after planting in treatments where inoculum moved to roots, roots grew to inoculum, and root-to-root spread occurred, respectively. No significant interactions between time and treatment were found.

$P$. capsici was recovered from roots of plants in all treatments. Propagule densities were highest in roots where sporangia and mycelia were buried directly in soil and all mechanisms of inoculum dispersal were possible at the final sampling time 24 days after planting (Fig. 6A). Disease severity on roots also increased over time and was highest initially in roots from plants where sporangia and mycelia were buried directly in soil and all mechanisms of dispersal were possible (Fig. 6B). Disease severity on roots was lower at the first sampling time, when zoospore inoculum moved to roots or roots grew through the wax layer to sporangia and mycelial inoculum or infected roots. Final disease severity on roots was uniformly high in all treatments, and the time-treatment interaction was not significant.

\section{DISCUSSION}

The mechanisms of primary inoculum dispersal in soil had large impacts on the development of Phytophthora blight epidemics. Disease incidence was greatest in both years in the field in plots

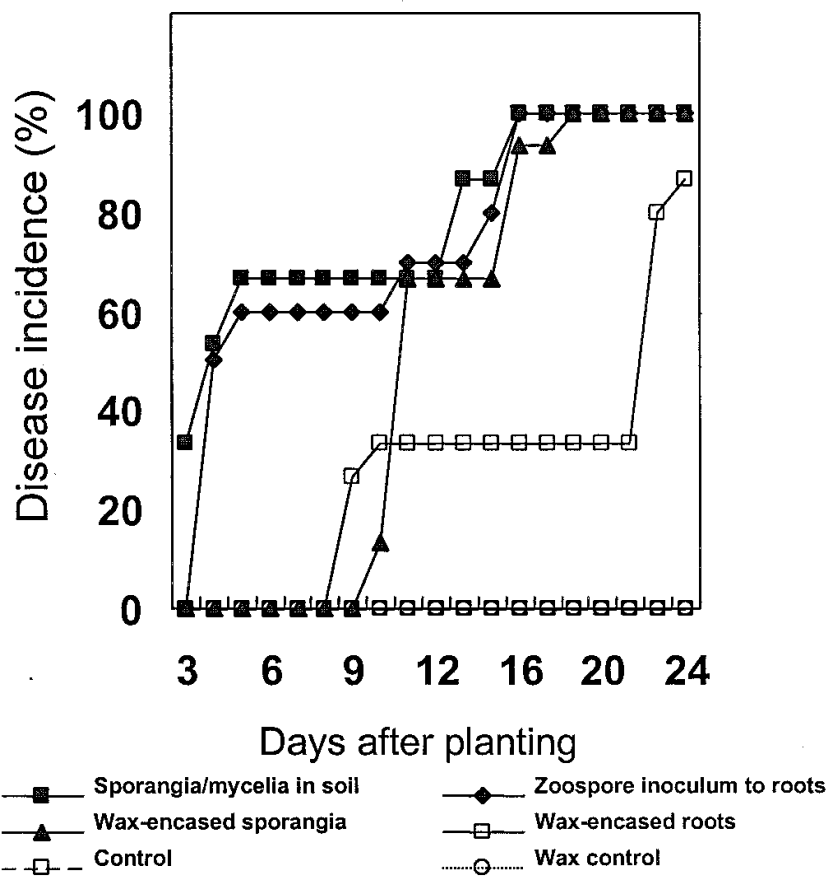

Fig. 5. Effect of components of primary inoculum dispersal in soil on temporal dynamics of disease caused by Phytophthora capsici on bell pepper seedlings grown in PVC tubes in tension funnels in a growth chamber. Treatments included sporangia and mycelia buried directly in soil (all mechanisms of dispersal), zoospore inoculation at soil surface (inoculum movement to roots), wax-encased sporangia and mycelia buried in soil (root growth to inoculum), wax-encased infected roots buried in soil (root-to-root spread), noninfested soil, and wax-encased noninfested soil. 
where sporangia and mycelia were buried directly in soil and all mechanisms of dispersal of inoculum were possible and where infected plants were placed in PVC tubes on the soil surface and inoculum movement to roots was possible. These field data are the first to clearly distinguish components of primary inoculum dispersal in the soil on the temporal dynamics of epidemics caused by a Phytophthora sp. Use of wax-encased inoculum sources allowed us to clearly separate the different inoculum sources and components of dispersal.

Rain events dispersed sporangia and zoospores from infected plants placed on the soil surface into soil and caused root infections. The amount of rainfall immediately after inoculation was higher in 1995 than 1996; this may explain why overall disease incidence was higher in 1995 than 1996. In both years of our study, disease
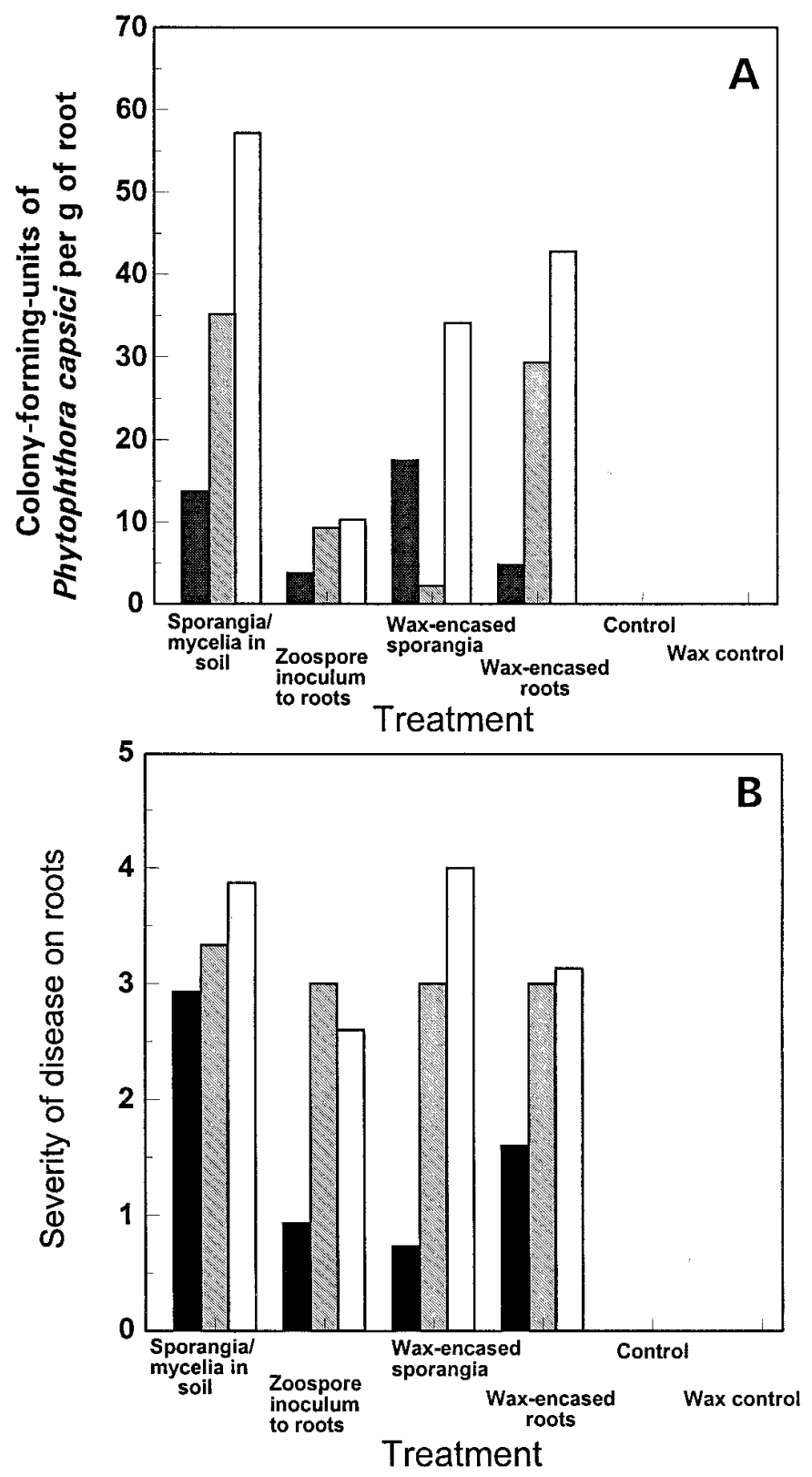

Fig. 6. Effect of components of primary inoculum dispersal in soil on $\mathbf{A}$, propagule densities of Phytophthora capsici in pepper roots, and $\mathbf{B}$, severity of root disease on pepper seedlings grown in tension funnels in a growth chamber. Black, gray, and white bars indicate sampling times at 11, 16, and 24 days after planting, respectively. Treatments included sporangia and mycelia buried directly in soil (all mechanisms of dispersal), zoospore inoculation at the soil surface (inoculum movement to roots), wax-encased sporangia and mycelia buried in soil (root growth to inoculum), wax-encased infected roots buried in soil(root-to-root spread), noninfested soil, and wax-encased noninfested soil. onset occurred first and, in one year, final incidence was greatest in plots where inoculum moved to roots from the infected plant source placed aboveground. A pepper plant with sporulating lesions was placed in a PVC cylinder in the middle of each quadrat. During periods of rainfall when soil was saturated, zoospores could have reached roots of plants more rapidly than in plots where roots had to grow to sporangial inoculum buried directly in soil. Also, infected plants with sporulating lesions could have produced greater numbers of sporangia earlier in the season, so more zoospores could have been released subsequently during periods of soil saturation than when sporangia were buried directly in soil. The incidence of root infection was higher than the incidence of disease on aboveground portions of plants in plots where inoculum movement to roots was the presumptive mechanism of dispersal, indicating that root infections preceded infections of the aboveground portions of the plants. The PVC tubes were in place for the entire season. Symptoms on aboveground portions of plants did not precede root infections; therefore, the presumptive mechanism of inoculum dispersal to roots was supported by our data.

In previous studies, we observed that epidemic onset occurs earlier and proceeds at rapid rates when inoculum, such as an infected fruit, is placed above the soil on black plastic surfaces (29). Also, previously published reports from our laboratory suggested that inoculum movement to roots in naturally infested fields plays an important role in spread of Phytophthora blight in commercial pepper fields $(16,28)$. The data presented here confirm these results. The soils in the coastal plain region of North Carolina where peppers are grown are sandy; zoospores released from sporangia can move rapidly in these soils to infect roots and crowns of plants. Zoospore movement in soils can be affected by soil texture and restricted in clay soils (10), but this was not the case in our field tests.

Disease on the aboveground portions of plants and roots also became severe when sporangia and mycelia were placed directly in soil. Inoculum was placed directly in soil; therefore, all mechanisms of dispersal, including root growth to inoculum, inoculum movement to roots, and root-to-root spread, were theoretically possible. High levels of inoculum also were recovered from soil early in epidemic development when inoculum was placed directly in soil, whereas low levels of inoculum were recovered from soils in most other treatments. The incidence of root infection was higher than the incidence of infection on aboveground portions of plants early in epidemic development in plots where sporangia and mycelia were buried directly in soil, suggesting that root infections had occurred.

Phytophthora blight on pepper is a polycyclic disease and multiple cycles of inoculum production and dispersal occur during epidemic development. Propagule densities of $P$. capsici in soil increased as disease incidence increased early in epidemic development in plots where sporangia and mycelia were buried directly in soil. In previous work, the largest increases in propagule densities of $P$. capsici occurred in soil containing root tissues for colonization by the pathogen (26). These increases were due to secondary inoculum production followed by release of zoospores in soil during saturation periods (26). There was increased incidence of root infection in plots where sporangia and mycelia were placed directly in soil and all mechanisms of dispersal were possible and where infected plants were placed in PVC tubes and inoculum movement to roots occurred. Early disease onset in these plots led to rapid disease increase and rapid production of secondary inoculum during periods of soil saturation. The highest population densities of $P$. capsici were recovered from infected roots at early stages of the epidemic and decreased dramatically over time. This is consistent with our earlier findings (26) that population densities of $P$. capsici in the soil around plants at early stages of root infection were much higher than around plants in plots where epidemics were more advanced. Propagule densities of $P$. capsici did not remain high in soils from these treatments but decreased over time, probably as root tissue available for colonization decreased. 
Phytophthora blight occurred in plots where wax-encased sources of inoculum or infected roots were buried in soil, but incidence was low. In both treatments, roots had to grow to sources of inoculum before disease onset could occur. In monocyclic diseases, in addition to the depth of infection, root growth is probably the major limiting factor for pathogen dispersal and development of epidemics $(9,12)$. On the other hand, onset and progress of disease can be affected by plant distance from the introduced point source and root density (22). In our studies, the point source of wax-encased inoculum was introduced in the middle of a quadrat $3 \mathrm{~m}$ long. By the end of the season, we found few roots penetrating the waxencased inoculum, and the lower disease incidence and rate of epidemic development probably resulted from low root growth into the wax-encased inoculum source. In both years, disease onset was significantly delayed in plants in these plots until root growth to the inoculum sources had occurred.

The depth of placement of the wax-encased inoculum source in soil also may have impacted disease progress. In our experiments, inoculum was placed in wax-encased pots below the drip-irrigation emitters. Irrigation stimulates zoospore release and dispersal of Phytophthora spp. in soil and also stimulates root growth, making root contact with inoculum more probable $(24,25)$. Deep subsurface irrigation encourages root growth deep in the soil profile where inoculum and root contact can be minimized (7). In our experiments, most of the roots from adjacent plants grew toward the drip irrigation source, and these roots may have grown above the wax-encased inoculum buried below the drip line. We observed wilted plants and plants with crown lesions in plots where waxencased inoculum or roots were buried in soil, indicating that root infections had occurred. However, the pathogen did not spread to plants at the ends of the quadrats by the end of the season because there were low levels of inoculum in soil in these plots. Some roots did penetrate wax-encased pots, indicating that the presumed process of root growth into the inoculum source was operative, but the incidence of root infection was low in these plots. The peat pots remained intact through the growing season, and little inoculum was found in the soil outside the wax-encased pots at any sampling time.

Results from the growth-chamber studies confirmed the field experiments and demonstrated that when sporangia and mycelia were placed directly in soil and all mechanisms of dispersal were operative and when zoospore inoculum movement to roots occurred disease progressed rapidly. Delays in disease onset were apparent when roots had to grow to inoculum or to infected roots beyond a wax layer, but final incidence was high in all treatments. The volume of soil placed in the PVC cylinders in the growth chamber studies was small compared with the soil volume in inoculated field plots. Many roots penetrated the wax layer by the end of the experiment, and root disease severity was high in plants in these treatments by the end of the experiment. Also, constant temperature and soil water matric potential in funnels were favorable for disease development in the growth chamber and contributed to high levels of disease. Our data indicate that infection via root-toroot spread is possible for $P$. capsici in soil.

Disease significantly reduced yield in plots where all mechanisms of dispersal and inoculum movement to roots were operative in 1995. Overall, yields in the control plots were higher in 1995 than in 1996. This may have been due to differences in rainfall between the two seasons. In 1995, $44.3 \mathrm{~cm}$ of rainfall occurred during June and July whereas, in 1996, only $23.1 \mathrm{~cm}$ of rainfall occurred during the same time period during fruit set.

Through carefully designed field and growth-chamber experiments, we were able to clearly separate the components of primary inoculum dispersal of $P$. capsici in soil. The mechanism of dispersal of the primary inoculum in soil can have large impacts on disease onset, progress, and final incidence. Our data also provide the first evidence that root-to-root spread also may lead to epidemic development in Phytophthora blight in bell pepper in the field. The challenge now is to reduce the dispersal of inoculum of $P$. capsici with ecologically based approaches and to manage the disease more effectively in the field.

\section{ACKNOWLEDGMENTS}

This research was funded in part by grant $92-37303-7715$ from the National Research Initiatives Competitive Grants Program, U.S. Department of Agriculture, and in part by the North Carolina Agricultural Research Service. Discussions with and the assistance of C. L. Campbell and C. Harper with aspects of this work are greatly appreciated.

\section{LITERATURE CITED}

1. Biles, C. L., Lindsey, D. L., and Liddell, C. M. 1992. Control of Phytophthora root rot of chili peppers by irrigation practices and fungicides. Crop Prot. 11:225-228.

2. Bowers, J. H. 1990. Effect of soil temperature and soil-water matric potential on the survival of Phytophthora capsici in natural soil. Plant Dis. 74:771-777.

3. Bowers, J. H., and Mitchell, D. J. 1991. Relationship between inoculum level and Phytophthora capsici and mortality of pepper. Phytopathology 81:178-184.

4. Bowers, J. H., Sonoda, R. M., and Mitchell, D. J. 1990. Path coefficient analysis of the effect of rainfall variables on the epidemiology of Phytophthora blight of pepper caused by Phytophthora capsici. Phytopathology 80:1439-1446.

5. Café-Filho, A. C., and Duniway, J. M. 1995. Effects of furrow irrigation schedules and host genotype on Phytophthora root rot of pepper. Plant Dis. 79:39-43.

6. Café-Filho, A. C., and Duniway, J. M. 1995. Dispersal of Phytophthora capsici and $P$. parasitica in furrow-irrigated rows of pepper, tomato, and squash. Plant Dis. 79:44-48.

7. Café-Filho, A. C., and Duniway, J. M. 1996. Effect of location of drip irrigation emitters and position of Phytophthora capsici infections on roots on Phytophthora root rot of pepper. Phytopathology 86:1364-1369.

8. Campbell, C. L., Jacobi, W. R., Powell, N. T., and Main, C. E. 1984. Analysis of disease progression and the randomness of occurrence of infected plants during tobacco black shank epidemics. Phytopathology 74:230-235.

9. Crowe, F. J., and Hall, D. H. 1980. Vertical distribution of sclerotia of Sclerotium cepivorum and host root systems relative to white rot of onion and garlic. Phytopathology 70:70-73.

10. Duniway, J. M. 1976. Movement of zoospores of Phytophthora cryptogea in soils of various textures and matric potentials. Phytopathology 66: 877-882.

11. Hord, M. J., and Ristaino, J. B. 1992. Effect of the matric component of soil water potential on infection of pepper seedlings in soil infested with oospores of Phytophthora capsici. Phytopathology 82:792-798.

12. Huisman, O. C. 1982. Interrelations of root growth dynamics to epidemiology of root invading fungi. Annu. Rev. Phytopathol. 20:303-327.

13. Hwang, B. K., and Kim, C. H. 1995. Phytophthora blight of pepper and its control in Korea. Plant Dis. 79:221-227.

14. Kannwischer, M. E., and Mitchell, D. J. 1978. The influence of a fungicide on the epidemiology of black shank of tobacco. Phytopathology 68: 1760-1765.

15. Kreutzer, W. A., Bodine, E. W., and Durrell, L. W. 1940. Cucurbit disease and rot of tomato fruit caused by Phytophthora capsici. Phytopathology 30:972-976.

16. Larkin, R. P., Gumpertz, M. L., and Ristaino, J. B. 1995. Geostatistical analysis of Phytophthora capsici epidemics in commercial bell pepper fields. Phytopathology 85:191-203.

17. Leonian, L. 1922. Stem and fruit blight of peppers caused by Phytophthora capsici sp. nov. Phytopathology 12:401-408.

18. Masago, H., Yoshikawa, M., Fukada, M., and Nakanishi, N. 1977. Selective inhibition of Pythium spp. on a medium for direct isolation of Phytophthora spp. from soils and plants. Phytopathology 67:425-428.

19. Neher, D., and Duniway, J. M. 1992. Dispersal of Phytophthora parasitica in tomato fields by furrow irrigation. Plant Dis. 76:582-586.

20. Parra, G. P., and Ristaino, J. B. 1998. Insensitivity to ridomil gold (mefenoxam) found among field isolates of Phytophthora capsici causing Phytophthora blight on bell pepper in North Carolina and New Jersey. Plant Dis. 82:711.

21. Pennisi, A. M., Agosteo, G. E., Cacciola, S. O., Pane, A., and Faedda, R. 1998. Insensitivity to metalaxyl among isolates of Phytophthora capsici causing root and crown rot of pepper in southern Italy. Plant Dis. 82: 1283.

22. Pfender, W. E., and Hagendorn, D. J. 1983. Disease progress and yield loss in Aphanomyces root rot of peas. Phytopathology 73:1107-1113. 
23. Reynolds, K. M., Madden. L. V., and Ellis, M. A. 1988. Spatiotemporal analysis of epidemic development of leather rot of strawberry. Phytopathology 78:246-252.

24. Ristaino, J. B. 1991. Influence of rainfall, drip irrigation, and inoculum density on the development of Phytophthora root and crown rot epidemics and yield in bell pepper. Phytopathology 81:922-929.

25. Ristaino, J. B., Duniway, J. M., and Marois, J. J. 1988. Influence of frequency and duration of furrow irrigation on the development of Phytophthora root rot and yield in processing tomatoes. Phytopathology 78: 1701-1706.

26. Ristaino, J. B., and Hord, M. J. 1992. Population densities of Phytophthora capsici in the field soils in relation to drip irrigation, rainfall, and disease incidence. Plant Dis. 76:1017-1024.

27. Ristaino, J. B., and Johnston, S. B. 1999. Ecologically based approaches to management of Phytophthora blight on bell pepper. Plant Dis. 83:1080-1089.

28. Ristaino, J. B., Larkin, R. P., and Campbell, C. L. 1994. Spatial dynamics of disease symptom expression during Phytophthora epidemics in bell pepper. Phytopathology 84:1015-1024.

29. Ristaino, J. B., Parra, G., and Campbell, C. L. 1997. Suppression of Phytophthora blight in bell pepper by a no-till wheat cover crop. Phytopathology 87:242-249.

30. Schlub, R. C. 1983. Epidemiology of Phytophthora capsici on bell pepper. J. Appl. Sci. Cambridge 100:7-11.

31. Shew, H. D. 1987. Effect of host resistance on spread of Phytophthora parasitica var. nicotianae and subsequent development of tobacco black shank under field conditions. Phytopathology 77:1090-1093.

32. Sujkowski, L. S., Ristaino, J. B., Parra, G. R., and Gumpertz, M. L. 1996. Effect of dispersal of inoculum of Phytophthora capsici in soil on temporal dynamics of disease. (Abstr.) Phytopathology 86:S108.

33. Weber, G. F. 1932. Blight of peppers in Florida caused by Phytophthora capsici. Phytopathology 22:775-780.

34. Zwankhuizen, M. J., Govers, F., and Zadoks, J. C. 1998. Development of potato late blight epidemics: Disease foci, disease gradients, and infection sources. Phytopathology 88:754-763. 